\title{
Treatment strategies in mucous membrane pemphigoid
}

\author{
Ann G Neff \\ Matthew Turner \\ Diya F Mutasim
}

Department of Dermatology, University of Cincinnati, Cincinnati, $\mathrm{OH}$, USA
Correspondence: Dr. Diya Mutasim Department of Dermatology, University of Cincinnati Medical Center, 23I Albert Sabin Way, Medical Sciences Building, Room 7409, POB 670592, Cincinnati, Ohio 45267-0592, USA

$\mathrm{Tel}+$ I 5135581903

$\mathrm{Fax}+\mathrm{I} 5135580198$

Email diya.mutasim@uc.edu

\begin{abstract}
Mucous membrane pemphigoid (MMP) is an autoimmune blistering disorder that is characterized by subepithelial bullae. Various basement membrane zone components have been identified as targets of autoantibodies in MMP. Considerable variability exists in the clinical presentation of MMP. Mucous membranes that may be involved include the oral cavity, conjunctiva, nasopharynx, larynx, esophagus, genitourinary tract, and anus. A multidisciplinary approach is essential in the management of MMP. Early recognition of this disorder and treatment may decrease disease-related complications. The choice of agents for treatment of MMP is based upon the sites of involvement, clinical severity, and disease progression. For more severe disease, or with rapid progression, systemic corticosteroids are the agents of choice for initial treatment, combined with steroid-sparing agents for long-term maintenance. Due to the rarity of this disease, large controlled studies comparing the efficacy of various agents are lacking.

Keywords: mucous membrane pemphigoid, cicatricial pemphigoid
\end{abstract}

\section{Clinical findings and diagnosis}

Mucous membrane pemphigoid (MMP) is an autoimmune blistering disorder of mucous membranes that is characterized by subepithelial bullae (Chan et al 2002; Egan et al 2003; Thorne et al 2004). Mucous membranes that may be involved include the oral cavity, conjunctiva, nasopharynx, larynx, esophagus, genitourinary tract, and anus. The oral mucosa is most commonly involved, followed by the conjunctiva (Thorne et al 2004). The skin is involved in approximately one-quarter of patients (Ahmed and Hombal 1986), often limited to the head, neck, and upper torso regions (Figure 1).

Various basement membrane zone components have been identified as targets of autoantibodies in MMP. These include bullous pemphigoid antigen 1 (BPAg1, $230 \mathrm{kd}$ ) (Bernard et al 1990), bullous pemphigoid antigen 2 (BPAg2, $180 \mathrm{kd}$ ) (Balding et al 1996), laminin 5 (Domloge-Hultsch et al 1994), laminin 6 (Chan et al 1997), $\alpha_{6}$-integrin subunit (Rashid et al 2006b), $\beta_{4}$-integrin subunit (Tyagi et al 1996), collagen VII (Luke et al 1999; Wieme et al 1999), and other proteins of unknown identity and/or function (Ghohestani et al 1996; Sarret et al 1989). There is no definitive evidence linking specific disease phenotypes with particular target antigens. However, a recent study found that sera of patients with cicatricial ocular disease and generalized MMP contained antibodies to $\beta_{4}$-integrin, and sera of those with oral MMP contained antibodies to $\alpha_{6}$-integrin (Rashid et al 2006a). These patients maintained selectivity to the target antigen throughout their clinical course.

Diagnosis of MMP rests mainly upon the clinical findings and immunofluorescence studies. Histopathologic examination reveals a subepithelial blister with a variable inflammatory cell infiltrate. Direct immunofluorescence of perilesional mucosa or skin is essential for diagnosis, and reveals linear deposition of $\mathrm{IgG}, \mathrm{C} 3$, or less commonly IgA along the basement membrane zone (Fine et al 1984; Leonard et al 1988; Rogers et al 1977). The use of salt split skin or mucosal epithelium for indirect 


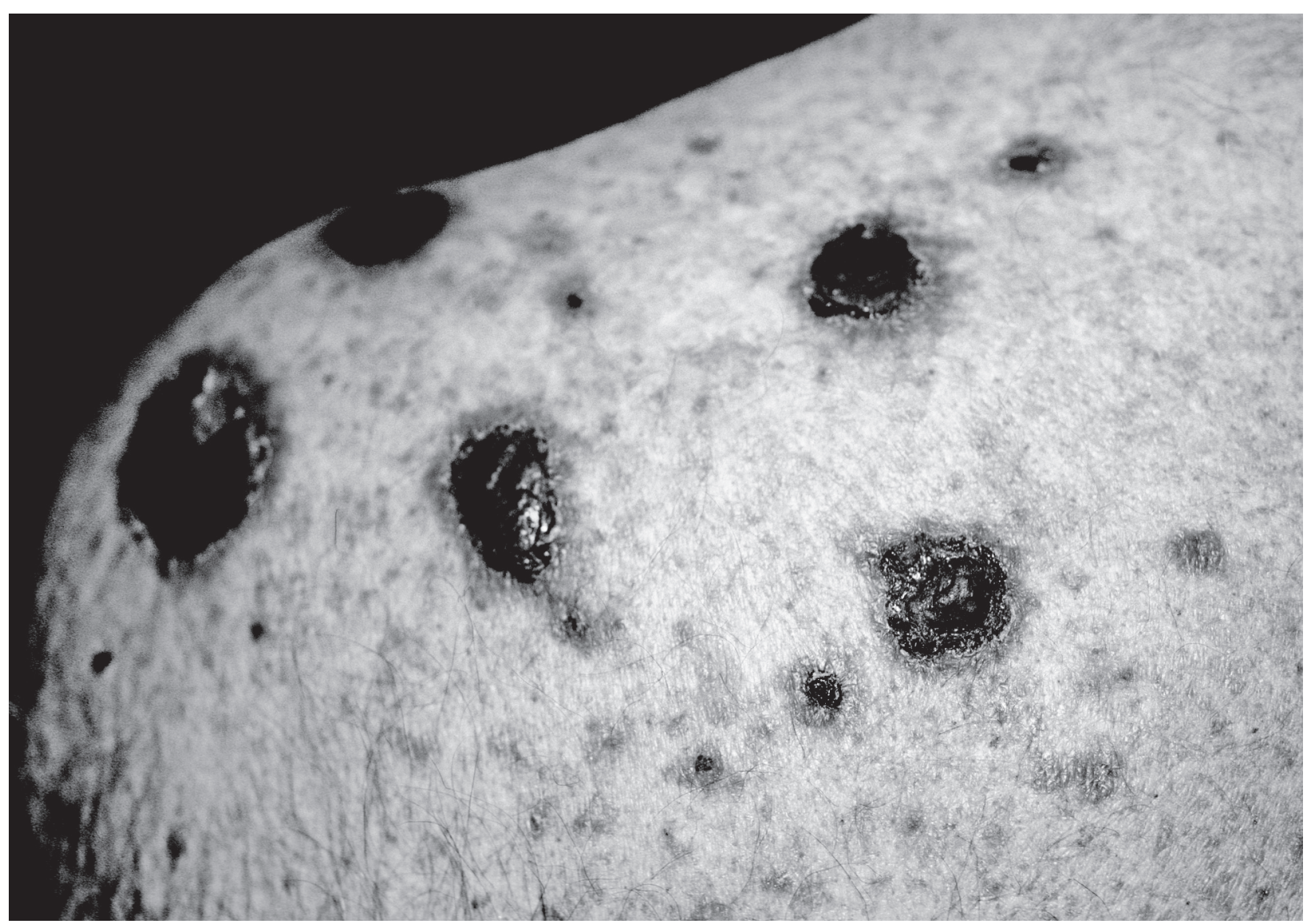

Figure I Vesicles and erosions on the trunk.

immunofluorescence studies may increase the sensitivity of this technique. Indirect immunofluorescence utilizing salt split skin may reveal binding to the roof and/or floor depending upon the antigen targeted (Ghohestani et al 1997; Kelly and Wojnarowska 1988).

Considerable variability exists in the clinical presentation of MMP. Patients may present with only one mucosal or skin site involved, or any combination of sites. Manifestations of oral disease, the most common site of involvement, include vesicles, erosions, desquamative gingivitis, and occasional scarring (Figure 2). Scarring is common at nonoral sites of involvement, contributing to disease-related morbidity.

Ocular complications of MMP result from conjunctival erosions with subsequent scarring and progressive cicatrization with foreshortening of the fornices (Elder et al 1996). The palpebral conjunctiva lining the lids may fuse with the bulbar conjunctiva, resulting in symblepharon or scar bands between the lid and globe (Figure 3). The scarring of the conjunctiva also results in loss of goblet cells with subsequent dry eye and disruption of the corneal epithelium (Ralph 1975).

Eyelid malposition is also a common occurrence, with entropion or inward turning of the lid margin resulting from the scarring process of the conjunctiva (Faraj and HoangXuan 2001; Shiu and McNab 2005) (Figure 4). This results in inadequate ocular surface protection and abrasion of the ocular surface by misdirected eyelashes, further compromising the corneal integrity and contributing to corneal scarring and neovascularization. Blindness and even loss of the globe due to perforation and endophthalmitis may occur (Messmer et al 2000; Nouri et al 2001).

Anogenital involvement presents with blisters and erosions that may result in scarring. Severe vulvar scarring and phimosis have been reported (Frith et al 1991; Fueston et al 2002; Goldstein et al 2005). Life-threatening complications may result from involvement of the larynx, esophagus, and rarely the lower airway (Muller and Salzer 1988; Anstey et al 1991; Alexandre et al 2006; Gamm et al 2006).

\section{Management}

A multidisciplinary approach is essential in the management of MMP. Early recognition and treatment may decrease disease-related complications. In a patient who presents with involvement of one site, a thorough review of symptoms highlighting other potential areas of involvement should 


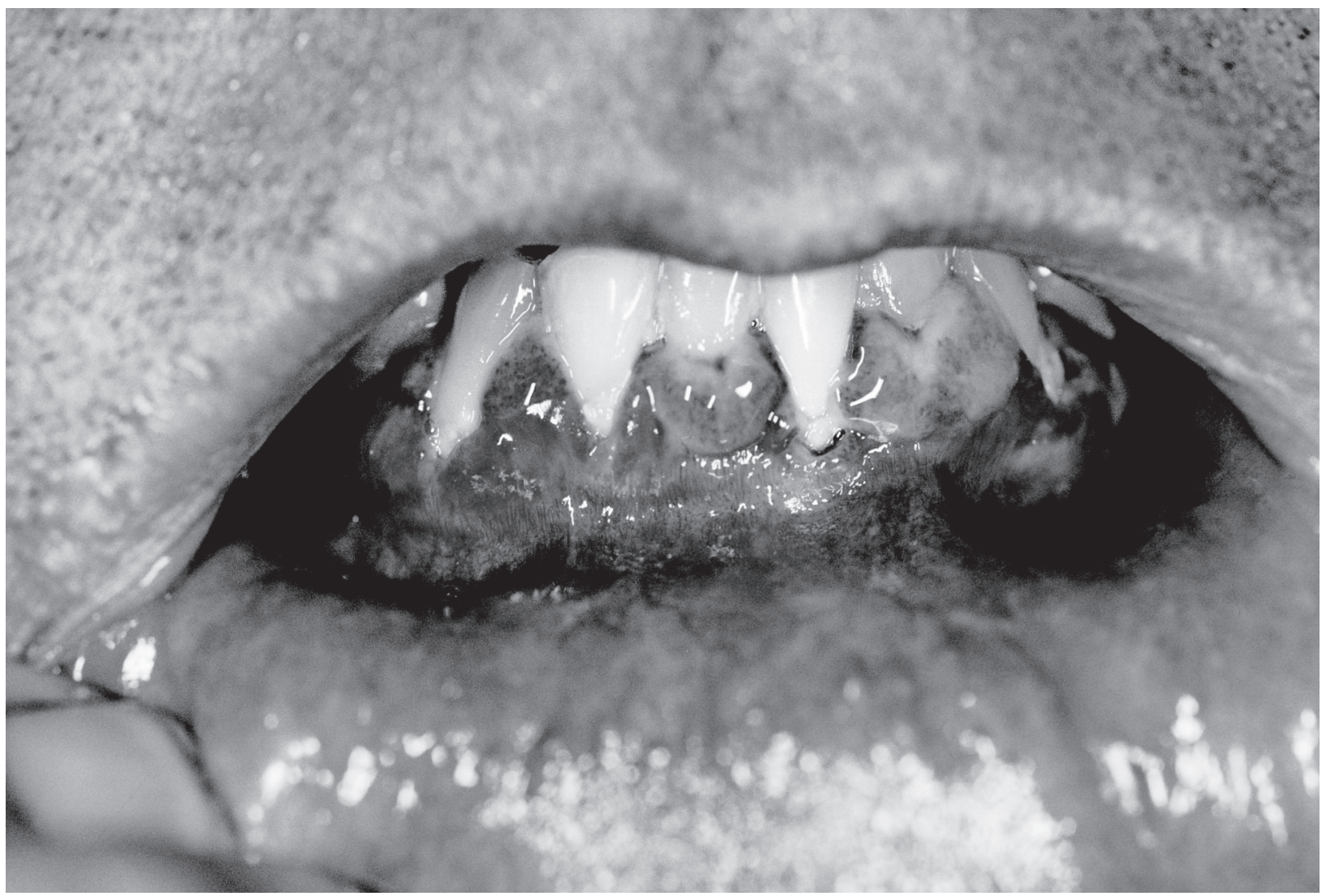

Figure 2 Gingival erosions.

be obtained. The choice of agents for treatment of MMP is based upon the sites of involvement, clinical severity, and disease progression.

Unfortunately, large randomized controlled trials comparing the efficacy of various agents in the treatment of MMP are lacking in the literature, but there is general consensus on the guidelines of treatment based on clinical experience. The First International Consensus on MMP recommended dividing patients into "low-risk" and "high-risk" groups based upon the site(s) of involvement, with "low-risk" patients defined as having only oral mucosal or oral and skin involvement (Chan et al 2002). "High-risk" patients were defined as having involvement of the ocular, genital, nasopharyngeal, esophageal, and/or laryngeal mucosae, and require more aggressive treatment.

\section{Mild disease}

For mild disease without rapid progression, dapsone may be initiated at 25 to $50 \mathrm{mg}$ per day, increasing monthly by 25 to $50 \mathrm{mg}$ until clinical remission is achieved or until the maximum tolerated dose is reached (usually $200 \mathrm{mg}$ per day). Successful use of this agent has been reported in patients with moderate to severe oral disease, and ocular disease as well (Ciarrocca and Greenberg 1999; Miserocchi et al 2002).
Failure to develop marked improvement within approximately 3 months should prompt consideration of another agent such as azathioprine, methotrexate, or cyclophosphamide if the disease is affecting a high-risk site such as the ocular surface.

Appropriate pretreatment laboratory studies must be performed, including a glucose-6-phosphate dehydrogenase level due to the risk of hemolysis. Monitoring during therapy is required to assess for adverse effects including dose-related hemolytic anemia and methemoglobinemia, and other idiosyncratic side effects such as agranulocytosis and hepatitis (Raizman et al 1994; Miserocchi et al 2002; Wertheim et al 2006). Fatal hypersensitivity syndrome has been reported with the use of dapsone in other disease settings (Agrawal and Agarwalla 2005; Kosseifi et al 2006).

\section{Severe disease Systemic therapy Corticosteroids}

For more severe disease, or with rapid progression, systemic corticosteroids are the agents of choice for initial treatment, combined with steroid-sparing agents for long-term maintenance. Prednisone is usually given at a dose of $1-1.5 \mathrm{mg} / \mathrm{kg} /$ day, with appropriate monitoring for side effects. 


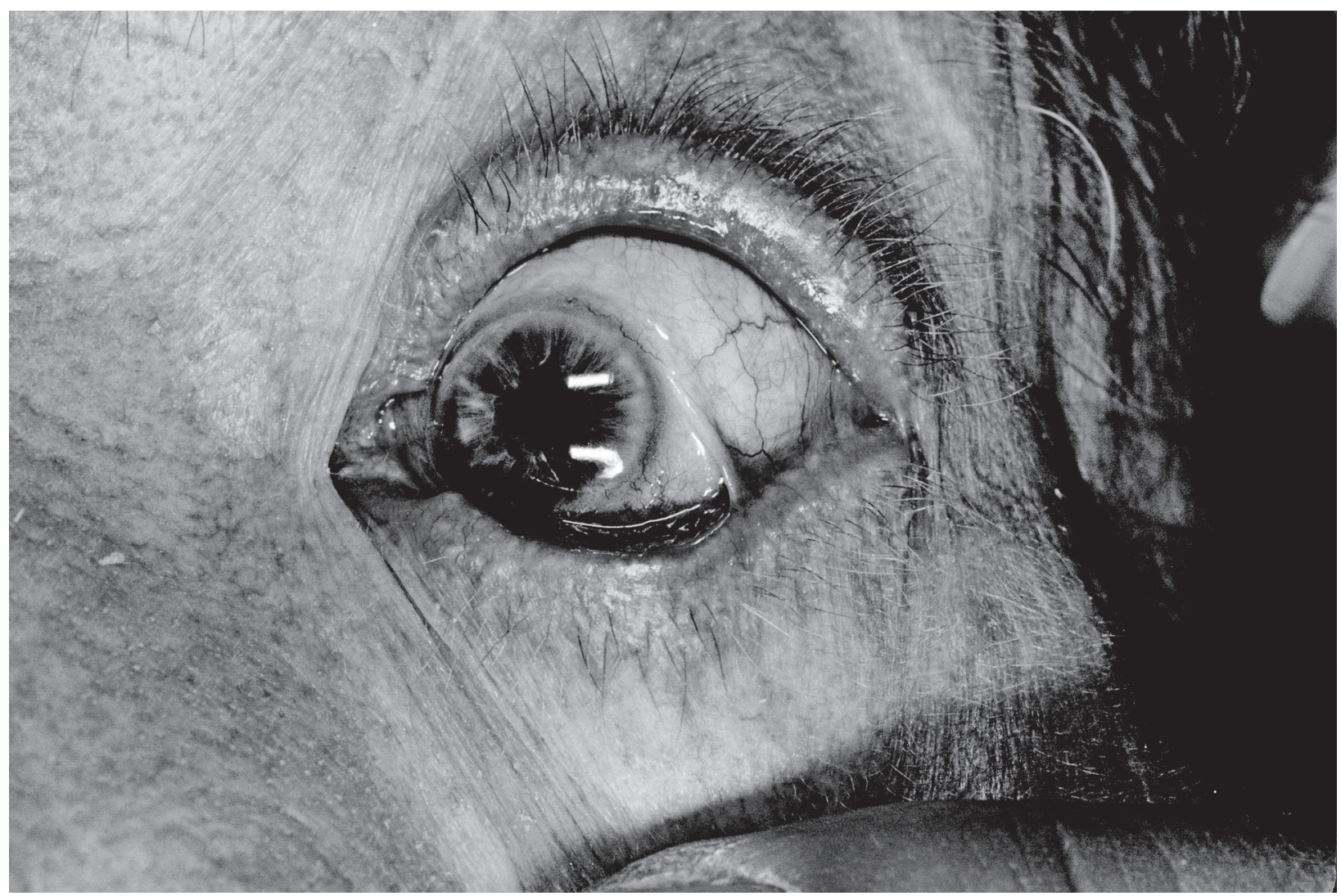

Figure 3 Conjunctival inflammation and symblepharon.

Therapy with prednisone lasts several months. Accordingly, calcium and vitamin D supplementation, along with bisphosphonate therapy and baseline dual energy X-ray absorptiometry (DEXA) scanning, should be considered. Once patients achieve and maintain clinical remission, the steroid dose is decreased gradually. Generally, the adjuvant immunosuppressive drug is continued for approximately two years.

\section{Cyclophosphamide}

Cyclophosphamide has been the traditional steroid-sparing agent of choice for patients with severe disease or rapid progression. It is started in conjunction with systemic steroids (Brody and Pirozzi 1977; Elder et al 1995). Cyclophosphamide is an alkylating agent that suppresses B cell function greater than $\mathrm{T}$ cell function, and has significant potential adverse effects such as bone marrow suppression, carcinogenesis, and teratogenicity (Baker et al 1987). Dosage usually ranges between 1 to $2.5 \mathrm{mg} / \mathrm{kg} /$ day or 50 to $200 \mathrm{mg}$ per day when administered orally, and between 0.5 to $1 \mathrm{~g} / \mathrm{m}^{2}$ when given as monthly intravenous (IV) pulse therapy (Pandya et al 1997). IV infusion given as a three day pulse can be particularly helpful when rapid control is needed, for instance prior to ocular surface surgery (Yesudian et al 2005).
There is evidence that cyclophosphamide is more effective than dapsone in controlling disease (Kirtschig et al 2002), but large controlled studies are lacking. Awareness of the potential adverse effects of cyclophosphamide is critical to allow appropriate monitoring during therapy.

Several other steroid-sparing agents have been used in the treatment of MMP. For patients with mild disease that fail or are intolerant of dapsone, or for those with more severe disease that are not candidates for therapy with cyclophosphamide, azathioprine and methotrexate are potential alternative agents (Dave and Vickers 1974; Mondino and Brown 1983; McCluskey et al 2004). Recent reports have also noted the successful use of mycophenolate mofetil in the treatment of MMP (Megahed et al 2001; Thorne et al 2005; Salzano et al 2006).

\section{Azathioprine}

Azathioprine undergoes conversion to 6-thioguanine by the enzyme hypoxanthine-guanine phosphoribosyltransferase. 6-thioguanine is an active purine analog that is incorporated into DNA and RNA with subsequent inhibition of purine metabolism and cell division. The exact mechanism of immunosuppression is not known. Dosage ranges from 


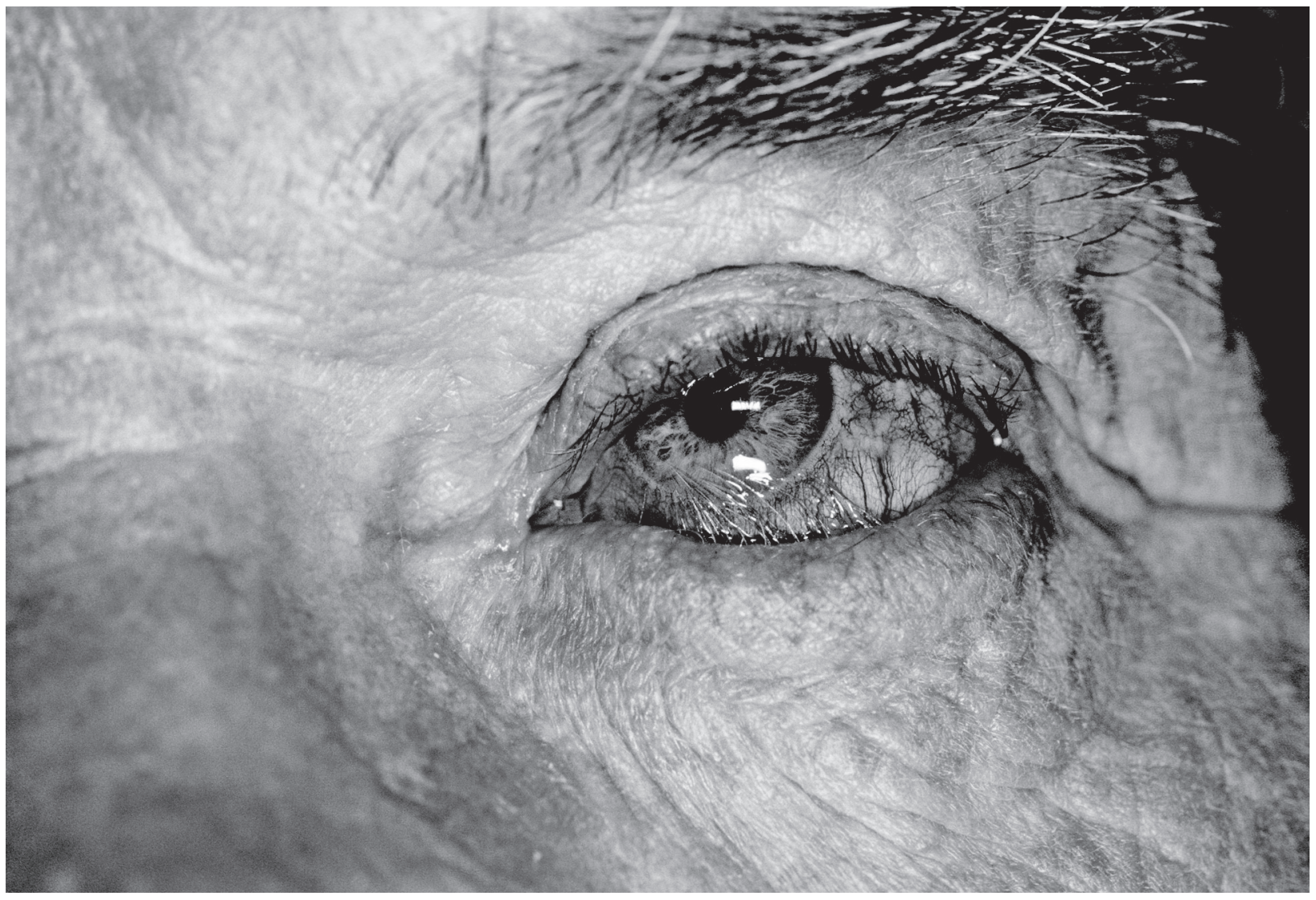

Figure 4 Conjunctival scarring has resulted in lower eyelid entropion.

$1-4 \mathrm{mg} / \mathrm{kg} /$ day depending upon the patient's thiopurine methyltransferase level. Azathioprine has been used effectively in the treatment of autoimmune bullous diseases, including MMP (Dave and Vickers 1974; Tauber et al 1991). Bialasiewicz and colleagues (1994) reported the successful use of azathioprine in 9 patients undergoing nasal mucosal grafting to the ocular surface. Miserocchi and colleagues (2002) noted 32 instances of treatment-related side effects in 23 patients treated with azathioprine.

Knowledge of the potential adverse reactions and appropriate monitoring are essential for the successful use of this agent. Serious adverse effects include leukopenia, pancytopenia, infection, malignancy and drug-induced hypersensitivity syndrome. The most common side effects are nausea, vomiting, and diarrhea, which may be improved by decreasing the dose, taking the medication with food, or giving divided doses. Appropriate monitoring includes periodic complete blood count and liver function testing.

\section{Methotrexate}

Methotrexate is an antimetabolite that irreversibly binds to dihydrofolate reductase. This prevents the conversion of dihydrofolate to tetrahydrofolate, a cofactor necessary for the synthesis of nucleotides needed in DNA and RNA synthesis. Immunosuppression results from inhibition of DNA synthesis in immunocompetent cells. McCluskey and colleagues (2004) reported on their use of methotrexate as a solo agent in the treatment of ocular MMP and drug-induced ocular MMP in 17 patients. Dosage ranged from 5 to $25 \mathrm{mg}$ given as a weekly dose. Mean duration of therapy was 15 months, ranging from 8-22 months. Control of ocular inflammation was achieved in $89 \%$ of patients with MMP and $100 \%$ of patients with drug-induced MMP. In a review of treatmentrelated side effects in 61 patients with MMP, Miserocchi and colleagues (2002) reported that methotrexate had the least number of adverse effects compared to azathioprine, cyclophosphamide, and dapsone.

Serious adverse effects may occur with methotrexate therapy. These include hepatotoxicity (liver fibrosis and cirrhosis), idiosyncratic acute pneumonitis, pulmonary fibrosis, pancytopenia, and malignancy. Gastrointestinal complaints such as nausea and anorexia are the most common side effects, frequently reduced by daily folic acid supplementation. Periodic laboratory monitoring includes complete blood 
count, renal panel, and liver function testing. Consideration should be given for liver biopsy after a cumulative dose of 1.5 grams, or sooner based on concomitant risk factors (such as prior hepatic disease, alcohol or intravenous drug abuse) and comorbidities (such as diabetes and obesity).

\section{Mycophenolate mofetil}

Mycophenolate mofetil inhibits the enzyme inosine monophosphate dehydrogenase, blocking de novo purine synthesis. This results in inhibition of the proliferative response of $\mathrm{B}$ and T cells. Dosage usually ranges from 1000 to $2000 \mathrm{mg}$ per day, but higher dosages may be required. Zurdel and colleagues (2001) reported the successful treatment of MMP in 9 of 10 eyes in 5 patients. Patients received $2000 \mathrm{mg}$ daily and were followed for at least 1 year. Gastrointestinal complaints were the most common side effect, but the drug is generally well-tolerated. Ingen-Housz-Oro and colleagues (2005) reported on their experience in treating 14 patients with mycophenolate mofetil after dapsone failed to control disease. Patients received 1500 to $2000 \mathrm{mg}$ daily in conjunction with dapsone. 10 of 14 patients achieved control of their disease, and 7 of these patients were able to decrease the dose of dapsone. Mycophenolate mofetil was ineffective in 4 of the 14 patients. More studies are needed to assess the efficacy of mycophenolate mofetil in the treatment of MMP.

Mycophenolate mofetil is usually well tolerated. Nausea, anorexia, and diarrhea may occur, and appear to be doserelated. Laboratory monitoring includes periodic complete blood count due to possible medication-induced leukopenia.

\section{Intravenous immunoglobulin}

Occasionally, patients present with progressive, recalcitrant disease despite treatment. For patients that fail therapy with systemic steroids and cyclophosphamide, or for those with rapidly progressive disease, high-dose intravenous immunoglobulin (IVIG) offers a therapeutic alternative. Over the last decade, there has been increased use of IVIG in the treatment of autoimmune and inflammatory skin diseases. Multiple different theories have been proposed to explain the mechanisms of action of IVIG. These include blockage of Fc receptors, alteration of cytokine production, cytokine antagonism, inhibition of complement-mediated damage, and neutralization of circulating autoantibodies (Andersson et al 1996; Jolles et al 1998). The successful use of IVIG in the treatment of MMP was initially reported in two patients (Urcelay et al 1997). Foster and Ahmed (1999) later reported on their experience in ten patients. Four to twelve cycles were required to achieve complete quiescence of conjunctival inflammation.
In long-term follow-up of these patients, the length of therapy ranged from 25-43 months (Sami et al 2004). Eight of the ten patients finished their study protocol, and all maintained remission after gradual withdrawal of IVIG therapy.

In a nonrandomized trial of 16 patients comparing the use of IVIG with conventional immunosuppression, IVIG was found to be more effective and safer than conventional therapy (Letko et al 2004). Studies evaluating the cost of IVIG therapy versus conventional therapy, both annually and over the total disease course, have suggested IVIG to be more cost-efficient than conventional immunosuppressive therapy (Daoud et al 2005; Daoud and Amin 2006). This was mainly attributed to the cost of treatment-related adverse effects in those given conventional immunosuppressive therapy. These findings have not been confirmed by other authors.

IVIG dosage ranges from 2 to $3 \mathrm{~g} / \mathrm{kg} / \mathrm{cycle}$, usually infused in divided doses over 3 to 5 days. The frequency of infusion varies from every 3 to 4 weeks initially, until disease activity subsides. The interval between cycles is then gradually increased as long as clinical remission is maintained. The endpoint of therapy has been suggested as a sustained clinical remission with two cycles 16 weeks apart (Sami et al 2004).

The most common adverse reaction related to IVIG use is an infusion reaction, and symptoms may include flushing, headache, chills, nausea, tachycardia, hypotension, and wheezing. The infusion should be slowed or discontinued based on the severity of the reaction. Premedication with an antihistamine and acetaminophen or intravenous steroid may be helpful in patients with a previous infusion reaction. Other rare adverse effects include anaphylaxis, disseminated intravascular coagulation, thrombosis, and acute renal failure. Pretreatment screening labs may include complete blood count, renal panel, liver function tests, hepatitis panel, HIV testing, IgA level, rheumatoid factor, and cryoglobulins. Periodic assessment of complete blood count, renal and liver panels, and HIV and hepatitis screening should be considered.

\section{Other treatment}

Successful treatment with other relatively new agents has recently been reported. Antitumor necrosis factor $\alpha$ agents, such as etanercept and infliximab, have been reported to be efficacious in the treatment of recalcitrant MMP (Sacher et al 2002; Canizares et al 2006; Heffernan and Bentley 2006). Daclizumab, an interleukin-2 receptor antagonist, was studied in a retrospective nonrandomized case series for the treatment of ocular inflammatory diseases. This study included the successful treatment of one patient with recalcitrant MMP 
using daclizumab monotherapy (Papaliodis et al 2003). The anti-CD20 agent rituximab has been successfully utilized in the treatment of pemphigus vulgaris (El Tal et al 2006) and bullous pemphigoid (Szabolcs et al 2002), and may be a useful agent for treatment-resistant MMP. Further studies are needed to assess the efficacy of these newer agents.

After discontinuation of systemic therapies, continued monitoring for disease activity is extremely important. Neumann and colleagues (1991) reported on their experience with 104 patients with MMP, noting that $22 \%$ of patients eventually relapsed after discontinuation of therapy. Patients also need to be monitored long-term for onset of disease at sites other than their initial areas of involvement (Thorne et al 2004; Higgins et al 2006).

\section{Topical therapy Oral disease}

Topical treatments are often used as adjunctive therapy in the treatment of MMP, and occasionally as monotherapy in patients with limited oral disease. Successful treatment of oral lesions has been reported with the use of topical steroids, tacrolimus, and cyclosporine (Aufdemorte et al 1985; Eisen et al 1990; Lozada-Nur et al 1991; Hall et al 2003; Assman et al 2004; Suresh et al 2006). Topical therapy of MMP involving the oral mucosa can be augmented with specialized application devices and administration at bedtime when oral secretions are relatively low.

\section{Ocular disease}

Although topical therapy alone has been successful in treating limited oral involvement, topical medications are used only as an adjunctive measure with systemic therapy in the treatment of ocular disease. Topical and subconjunctival corticosteroids may offer palliation of symptoms, but are ineffective in halting disease progression (Foster 1986).

Experience in treating ocular disease with topical formulations of the calcineurin inhibitors, cyclosporin A and tacrolimus, has been reported. Holland and colleagues (1993) noted lack of a therapeutic response to topical cyclosporine in a small series of patients. Hall and colleagues (2003), and more recently Michel and Gain (2006), reported successful use of topical tacrolimus in the treatment of one patient with MMP. Interestingly, systemic tacrolimus has not been found to be efficacious in controlling MMP (Letko et al 2001).

Mitomycin $\mathrm{C}$ is an alkylating agent that has been shown to inhibit DNA synthesis and fibroblast proliferation. Both topical and subconjunctival applications of mitomycin $\mathrm{C}$ have been described in the treatment of advanced ocular disease in MMP.
Secchi and Tognon (1996) treated ten eyes of five patients with intraoperative topical mitomycin $\mathrm{C}$ after surgical lysis of conjunctival synechiae. After 12-19 months of follow-up, no recurrences were noted. Donnenfeld and colleagues (1999) described the use of subconjunctival mitomycin $\mathrm{C}$ injection in the more severely affected eye of 9 patients with severe ocular MMP. After 12-40 months of follow-up, treated eyes showed less conjunctival erythema and shrinkage compared with the untreated control eyes. In contrast, Celis Sanchez and colleagues (2002) found no benefit of subconjunctival mitomycin $\mathrm{C}$ in preventing disease progression in 4 patients with severe ocular MMP.

\section{Prevention of scarring and complications}

Prevention of scarring and cicatrization is of utmost importance in the treatment of MMP, as surgical correction can be difficult and fraught with complications. Therefore, control of disease progression by halting inflammation is paramount. Patients should be followed by the appropriate subspecialists based upon the systems involved.

\section{Oral care}

Oral care includes appropriate dental hygiene, referral for dental care, monitoring for candidiasis, and topical anesthetics for pain. Soft, bland foods may cause less injury to eroded mucosa when disease is flaring. Fortunately, oral disease does not commonly result in functionally significant scarring.

\section{Eye care}

Eye care should be provided by an ophthalmologist as disease progression may be subtle. Ocular lubricants such as nonpreserved artificial tears, ointment, and gels are useful in improving surface lubrication. Placement of punctal plugs or punctal occlusion by cautery or surgery decreases tear drainage through the lacrimal drainage system. This can be helpful in increasing the tear lake, and increasing the retention of topically applied lubricants. Topical steroids may be used as adjunctive treatment, but should be dispensed and monitored by an ophthalmologist due to the risks of infection, increased intraocular pressure, and cataract. Squamous metaplasia with keratinization of the conjunctiva may be treated with topical retinoids formulated or compounded for use on the ocular surface.

Concomitant blepharitis should be recognized and treated appropriately. Classically divided into anterior and posterior varieties, blepharitis is an inflammation of the eyelids with bacterial colonization centered on the eyelashes and associated follicles or meibomian glands, respectively. 
Blepharitis can contribute to eyelid scarring with trichiasis, and cause conjunctival and corneal inflammation as well. Treatment consists of daily or twice daily warm compresses, followed by eyelid scrubs with diluted baby shampoo. Nightly application of a topical antibiotic ointment such as erythromycin or bacitracin is also helpful. For significant conjunctival or corneal inflammation, topical steroids in combination with an antibiotic are useful. For significant meibomian gland disease with inspissation and inflammation, oral tetracycline or doxycycline is often used.

Significant ocular scarring from MMP resulting in functional impairment may be amenable to surgical correction. However, repair should not be attempted until the disease is in remission. Premature interventions are likely to fail as surgical manipulation can cause flaring of disease.

Entropion with secondary trichiasis may be treated with cryotherapy, marginal rotation of the eyelid, or lid splitting with repositioning of the lash-bearing portion of the lid margin (Elder and Bernauer 1994; Elder and Collin 1996). Surgical reconstruction of the fornices may be accomplished with mucous membrane grafting or amniotic membrane grafting, possibly augmented with topical or subconjunctival mitomycin (Shore et al 1992; Barabino and Rolando 2003; Barabino et al 2003; Tseng et al 2005; Yesudian et al 2005).

Microbial keratitis may occur due to a combination of factors including ocular surface disease, dry eye, corneal exposure, and corneal anesthesia. Prompt culture and institution of broad spectrum topical antibiotics are essential for prevention of corneal perforation and subsequent endophthalmitis. Corneal perforation may also occur due to dry eye, particularly in combination with ocular surface inflammation, and also requires immediate intervention. Treatment options include procedures such as suturing, cyanoacrylate glue with bandage contact lens placement, and corneal grafting.

Corneal transplant can restore the clarity of the visual axis scarred from MMP, but stem cell deficiency, dry eye, lid malposition, and conjunctival inflammation can contribute to graft failure or rejection (Tugal-Tutkun et al 1995; Tsubota et al 1996). Limbal stem cell deficiency may be addressed with limbal stem cell grafting prior to corneal transplant to increase the success of the corneal graft. Placement of a keratoprosthesis or osteo-odonto-keratoprosthesis also offers an alternative for patients with severe visual disability due to end-stage scarring (Falcinelli et al 2005; Hollick et al 2006).

\section{Upper aerodigestive system}

Upper aerodigestive complications of disease include atrophic rhinitis, crusting, erosions, synechiae, stenoses, and potentially life-threatening laryngeal stenosis (Alexandre et al 2006). Treatment of the nasal manifestations may include local steroids and irrigation. Patients should be questioned regarding any nose and throat symptoms and referred for otolaryngology consultation (Whiteside et al 2003). Dysphagia due to esophageal strictures may occasionally occur and can be treated with esophageal dilation (Isolauri and Airo 1989; Syn and Ahmed 2004).

\section{Summary}

The diagnosis of MMP remains a challenge as patients may present to a variety of specialists, depending upon their initial symptomatology, and due to the diverse clinical manifestations. Maintaining a level of suspicion for the diagnosis is crucial for early recognition and treatment. Due to the relative rarity of this disorder, large, randomized controlled trials comparing the efficacy of various therapeutic agents are lacking. Therapy is guided by each individual patient's disease course and comorbid risk factors. A multidisciplinary approach aids in choosing the appropriate therapy, and improves patient outcomes.

\section{Disclosure}

The authors report no conflicts of interest.

\section{References}

Agrawal S, Agarwalla A. 2005. Dapsone hypersensitivity syndrome: a clinico-epidemiological review. J Dermatol, 32:883-9.

Ahmed AR, Hombal SM. 1986. Cicatricial pemphigoid. Int J Dermatol, 25:90-6.

Alexandre M, Brette MD, Pascal F, et al. 2006. A prospective study of upper aerodigestive tract manifestations of mucous membrane pemphigoid. Medicine (Baltimore), 85:239-52.

Andersson J, Skansen-Saphir U, Sparrelid E, et al. 1996. Intravenous immune globulin affects cytokine production in $\mathrm{T}$ lymphocytes and monocytes/macrophages. Clin Exp Immunol, 104:10-20.

Anstey A, Wojnarowska F, Whitehead P, et al. 1991. Oesophageal webs preceding carcinoma and rupture of the oesophagus in cicatricial pemphigoid. Clin Exp Dermatol, 16:395-8.

Assmann T, Becker J, Ruzicka T, et al. 2004. Topical tacrolimus for oral cicatricial pemphigoid. Clin Exp Dermatol, 29:674-6.

Aufdemorte TB, De Villez RL, Parel SM. 1985. Modified topical steroid therapy for the treatment of oral mucous membrane pemphigoid. Oral Surg Oral Med Oral Pathol, 59:256-60.

Baker GL, Kahl LE, Zee BC, et al. 1987. Malignancy following treatment of rheumatoid arthritis with cyclophosphamide. Long-term case-control follow-up study. Am J Med, 83:1-9.

Balding SD, Prost C, Diaz LA, et al. 1996. Cicatricial pemphigoid autoantibodies react with multiple sites on the BP180 extracellular domain. J Invest Dermatol, 106:141-6.

Barabino S, Rolando M, Bentivoglio G, et al. 2003. Role of amniotic membrane transplantation for conjunctival reconstruction in ocularcicatricial pemphigoid. Ophthalmology, 110:474-80.

Barabino S, Rolando M. 2003. Amniotic membrane transplantation elicits goblet cell repopulation after conjunctival reconstruction in a case of severe ocular cicatricial pemphigoid. Acta Ophthalmol Scand, $81: 68-71$. 
Bernard P, Prost C, Lecerf V, et al. 1990. Studies of cicatricial pemphigoid autoantibodies using direct immunoelectron microscopy and immunoblot analysis. J Invest Dermatol, 94:630-5.

Bialasiewicz AA, Forster W, Radig H, et al. 1994. Syngeneic transplantation of nasal mucosa and azathioprine medication for therapy of cicatricial ocular mucous membrane pemphigoid. Study of 9 patients with 11 eyes. Ophthalmologe, 91:244-50.

Brody HJ, Pirozzi DJ. 1977. Benign mucous membrane pemphigoid. Response to therapy with cyclophosphamide. Arch Dermatol, 113:1598-9.

Canizares MJ, Smith DI, Conners MS, et al. 2006. Successful treatment of mucous membrane pemphigoid with etanercept in 3 patients. Arch Dermatol, 142:1457-61.

Celis Sanchez J, Lopez Ferrando N, Garcia Largacha M, et al. 2002. Subconjunctival mitomycin $\mathrm{C}$ for the treatment of ocular cicatricial pemphigoid. Arch Soc Esp Oftalmol, 77:501-6.

Chan LS, Ahmed AR, Anhalt GJ, et al. 2002. The first international consensus on mucous membrane pemphigoid: definition, diagnostic criteria pathogenic factors, medical treatment, and prognostic indicators. Arch Dermatol, 138:370-9.

Chan LS, Majmudar AA, Tran HH, et al. 1997. Laminin-6 and laminin-5 are recognized by autoantibodies in a subset of cicatricial pemphigoid. J Invest Dermatol, 108:848-53.

Ciarrocca KN, Greenberg MS. 1999. A retrospective study of the management of oral mucous membrane pemphigoid with dapsone. Oral Surg Oral Med Oral Pathol Oral Radiol Endod, 88:159-63.

Daoud Y, Amin KG, Mohan K, et al. 2005. Cost of intravenous immunoglobulin therapy versus conventional immunosuppressive therapy in patients with mucous membrane pemphigoid: a preliminary study. Ann Pharmacother, 39:2003-8.

Daoud YJ, Amin KG. 2006. Comparison of cost of immune globulin intravenous therapy to conventional immunosuppressive therapy in treating patients with autoimmune mucocutaneous blistering diseases. Int Immunopharmacol, 6:600-6.

Dave VK, Vickers CF. 1974. Azathioprine in the treatment of mucocutaneous pemphigoid. Br J Dermatol, 90:183-6.

Domloge-Hultsch N, Anhalt GJ, Gammon WR, et al. 1994. Antiepiligrin cicatricial pemphigoid. A subepithelial bullous disorder. Arch Dermatol, 130:1521-9.

Donnenfeld ED, Perry HD, Wallerstein A, et al. 1999. Subconjunctival mitomycin $\mathrm{C}$ for the treatment of ocular cicatricial pemphigoid. Ophthalmology, 106:72-8; discussion 79.

Egan CA, Lazarova Z, Darling TN, et al. 2003. Anti-epiligrin cicatricial pemphigoid: clinical findings, immunopathogenesis, and significant associations. Medicine (Baltimore), 82:177-86.

Eisen D, Ellis CN, Voorhees JJ. 1990. Topical cyclosporine for oral bullous disorders. J Am Acad Dermatol, 23:936-7.

El Tal AK, Posner MR, Spigelman Z, et al. 2006. Rituximab: a monoclonal antibody to $\mathrm{CD} 20$ used in the treatment of pemphigus vulgaris. $J \mathrm{Am}$ Acad Dermatol, 55:449-59.

Elder MJ, Bernauer W, Leonard J, et al. 1996. Progression of disease in ocular cicatricial pemphigoid. Br J Ophthalmol, 80:292-6.

Elder MJ, Bernauer W. 1994. Cryotherapy for trichiasis in ocular cicatricial pemphigoid. Br J Ophthalmol, 78:769-71.

Elder MJ, Collin R. 1996. Anterior lamellar repositioning and grey line split for upper lid entropion in ocular cicatricial pemphigoid. Eye, 10:439-42.

Elder MJ, Lightman S, Dart JK. 1995. Role of cyclophosphamide and high dose steroid in ocular cicatricial pemphigoid. $\mathrm{Br} J$ Ophthalmol, 79:264-6.

Falcinelli G, Falsini B, Taloni M, et al. 2005. Modified osteo-odonto-keratoprosthesis for treatment of corneal blindness: long-term anatomical and functional outcomes in 181 cases. Arch Ophthalmol, 123:1319-29.

Faraj HG, Hoang-Xuan T. 2001. Chronic cicatrizing conjunctivitis. Curr Opin Ophthalmol, 12:250-7.

Fine JD, Neises GR, Katz SI. 1984. Immunofluorescence and immunoelectron microscopic studies in cicatricial pemphigoid. J Invest Dermatol, 82:39-43.
Foster CS, Ahmed AR. 1999. Intravenous immunoglobulin therapy for ocular cicatricial pemphigoid: a preliminary study. Ophthalmology, 106:2136-43.

Foster CS. 1986. Cicatricial pemphigoid. Trans Am Ophthalmol Soc, 84:527-663.

Frith P, Charnock M, Wojnarowska F. 1991. Cicatricial pemphigoid diagnosed from ocular features in recurrent severe vulval scarring. Two case reports. Br J Obstet Gynaecol, 98:482-4.

Fueston JC, Adams BB, Mutasim DF. 2002. Cicatricial pemphigoid-induced phimosis. J Am Acad Dermatol, 46:S128-9.

Gamm DM, Harris A, Mehran RJ, et al. 2006. Mucous membrane pemphigoid with fatal bronchial involvement in a seventeen-year-old girl. Cornea, 25:474-8.

Ghohestani RF, Nicolas JF, Rousselle P, et al. 1996. Identification of a $168-\mathrm{kDa}$ mucosal antigen in a subset of patients with cicatricial pemphigoid. J Invest Dermatol, 107:136-9.

Ghohestani RF, Nicolas JF, Rousselle P, et al. 1997. Diagnostic value of indirect immunofluorescence on sodium chloride-split skin in differential diagnosis of subepidermal autoimmune bullous dermatoses. Arch Dermatol, 133:1102-7.

Goldstein AT, Anhalt GJ, Klingman D, et al. 2005. Mucous membrane pemphigoid of the vulva. Obstet Gynecol, 105:1188-90.

Hall VC, Liesegang TJ, Kostick DA, et al. 2003. Ocular mucous membrane pemphigoid and ocular pemphigus vulgaris treated topically with tacrolimus ointment. Arch Dermatol, 139:1083-4.

Heffernan MP, Bentley DD. 2006. Successful treatment of mucous membrane pemphigoid with infliximab. Arch Dermatol, 142:1268-70.

Higgins GT, Allan RB, Hall R, et al. 2006. Development of ocular disease in patients with mucous membrane pemphigoid involving the oral mucosa. Br J Ophthalmol, 90:964-7.

Holland EJ, Olsen TW, Ketcham JM, et al. 1993. Topical cyclosporin A in the treatment of anterior segment inflammatory disease. Cornea, 12:413-19.

Hollick EJ, Watson SL, Dart JK, et al. 2006. Legeais BioKpro III keratoprosthesis implantation: long term results in seven patients. $\mathrm{Br} J$ Ophthalmol, 90:1146-51.

Ingen-Housz-Oro S, Prost-Squarcioni C, Pascal F, et al. 2005. [Cicatricial pemphigoid: treatment with mycophenolate mofetil]. Ann Dermatol Venereol, 132:13-16.

Isolauri J, Airo I. 1989. Benign mucous membrane pemphigoid involving the esophagus: a report of two cases treated with dilation. Gastrointest Endosc, 35:569-71.

Jolles S, Hughes J, Whittaker S. 1998. Dermatological uses of high-dose intravenous immunoglobulin. Arch Dermatol, 134:80-6.

Kelly SE, Wojnarowska F. 1988. The use of chemically split tissue in the detection of circulating anti-basement membrane zone antibodies in bullous pemphigoid and cicatricial pemphigoid. Br J Dermatol, 118:31-40.

Kirtschig G, Murrell D, Wojnarowska F, et al. 2002. Interventions for mucous membrane pemphigoid/cicatricial pemphigoid and epidermolysis bullosa acquisita: a systematic literature review. Arch Dermatol, 138:380-4.

Kosseifi SG, Guha B, Nassour DN, et al. 2006. The Dapsone Hypersensitivity Syndrome revisited: a potentially fatal multisystem disorder with prominent hepatopulmonary manifestations. J Occup Med Toxicol, 1:9.

Leonard JN, Hobday CM, Haffenden GP, et al. 1988. Immunofluorescent studies in ocular cicatricial pemphigoid. $\mathrm{Br} J$ Dermatol, 118:209-17.

Letko E, Ahmed AR, Foster CS. 2001. Treatment of ocular cicatricial pemphigoid with tacrolimus (FK 506). Graefes Arch Clin Exp Ophthalmol, 239:441-4.

Letko E, Miserocchi E, Daoud YJ, et al. 2004. A nonrandomized comparison of the clinical outcome of ocular involvement in patients with mucous membrane (cicatricial) pemphigoid between conventional immunosuppressive and intravenous immunoglobulin therapies. Clin Immunol, 111:303-10. 
Lozada-Nur F, Huang MZ, Zhou GA. 1991. Open preliminary clinical trial of clobetasol propionate ointment in adhesive paste for treatment of chronic oral vesiculoerosive diseases. Oral Surg Oral Med Oral Pathol, 71:283-7.

Luke MC, Darling TN, Hsu R, et al. 1999. Mucosal morbidity in patients with epidermolysis bullosa acquisita. Arch Dermatol, 135:954-9.

McCluskey P, Chang JH, Singh R, et al. 2004. Methotrexate therapy for ocular cicatricial pemphigoid. Ophthalmology, 111:796-801.

Megahed M, Schmiedeberg S, Becker J, et al. 2001. Treatment of cicatricial pemphigoid with mycophenolate mofetil as a steroid-sparing agent. $J$ Am Acad Dermatol, 45:256-9.

Messmer EM, Hintschich CR, Partscht K, et al. 2000. Ocular cicatricial pemphigoid. Retrospective analysis of risk factors and complications. Ophthalmologe, 97:113-20.

Michel JL, Gain P. 2006. Topical tacrolimus treatment for ocular cicatricial pemphigoid. Ann Dermatol Venereol, 133:161-4.

Miserocchi E, Baltatzis S, Roque MR, et al. 2002. The effect of treatment and its related side effects in patients with severe ocular cicatricial pemphigoid. Ophthalmology, 109:111-18.

Mondino BJ, Brown SI. 1983. Immunosuppressive therapy in ocular cicatricial pemphigoid. Am J Ophthalmol, 96: 453-9.

Muller LC, Salzer GM. 1988. Stenosis of left mainstem bronchus in a case of cicatricial pemphigoid. Eur J Cardiothorac Surg, 2:284-6.

Neumann R, Tauber J, Foster CS. 1991. Remission and recurrence after withdrawal of therapy for ocular cicatricial pemphigoid. Ophthalmology, 98:858-62.

Nouri M, Terada H, Alfonso EC, et al. 2001. Endophthalmitis after keratoprosthesis: incidence, bacterial causes, and risk factors. Arch Ophthalmol, 119:484-9.

Pandya AG, Warren KJ, Bergstresser PR. 1997. Cicatricial pemphigoid successfully treated with pulse intravenous cyclophosphamide. Arch Dermatol, 133:245-7.

Papaliodis GN, Chu D, Foster CS. 2003. Treatment of ocular inflammatory disorders with daclizumab. Ophthalmology, 110:786-9.

Raizman MB, Fay AM, Weiss JS. 1994. Dapsone-induced neutropenia in patients treated for ocular cicatricial pemphigoid. Ophthalmology, 101:1805-7.

Ralph RA. 1975. Conjunctival goblet cell density in normal subjects and in dry eye syndromes. Invest Ophthalmol, 14:299-302.

Rashid KA, Gurcan HM, Ahmed AR. 2006a. Antigen specificity in subsets of mucous membrane pemphigoid. J Invest Dermatol, 126:2631-6.

Rashid KA, Stern JN, Ahmed AR. 2006b. Identification of an epitope within human integrin alpha 6 subunit for the binding of autoantibody and its role in basement membrane separation in oral pemphigoid. J Immunol, 176:1968-77.

Rogers RS, 3rd, Perry HO, Bean SF, et al. 1977. Immunopathology of cicatricial pemphigoid: studies of complement deposition. $J$ Invest Dermatol, 68:39-43.

Sacher C, Rubbert A, Konig C, et al. 2002. Treatment of recalcitrant cicatricial pemphigoid with the tumor necrosis factor alpha antagonist etanercept. J Am Acad Dermatol, 46:113-15.

Salzano S, Arduino P, Zambruno G, et al. 2006. OC9 Successful use of mycophenolate mofetil in combination with minocycline in a woman with severe predominantly oral mucous membrane pemphigoid: a case report. Oral Dis, 12:11.

Sami N, Letko E, Androudi S, et al. 2004. Intravenous immunoglobulin therapy in patients with ocular-cicatricial pemphigoid: a long-term follow-up. Ophthalmology, 111:1380-2.
Sarret Y, Reano A, Nicolas JF, et al. 1989. Bullous pemphigoid and cicatricial pemphigoid: immunoblotting detection of involved autoantigens. Autoimmunity, 2:145-53.

Secchi AG, Tognon MS. 1996. Intraoperative mitomycin C in the treatment of cicatricial obliterations of conjunctival fornices. Am J Ophthalmol, 122:728-30.

Shiu M, McNab AA. 2005. Cicatricial entropion and trichiasis in an urban Australian population. Clin Experiment Ophthalmol, 33:582-5.

Shore JW, Foster CS, Westfall CT, et al. 1992. Results of buccal mucosal grafting for patients with medically controlled ocular cicatricial pemphigoid. Ophthalmology, 99:383-95.

Suresh L, Martinez Calixto LE, Radfar L. 2006. Successful treatment of mucous membrane pemphigoid with tacrolimus. Spec Care Dentist, 26:66-70.

Syn WK, Ahmed MM. 2004. Esophageal involvement in cicatricial pemphigoid: a rare cause of dysphagia. Dis Esophagus, 17:180-2.

Szabolcs P, Reese M, Yancey KB, et al. 2002. Combination treatment of bullous pemphigoid with anti-CD20 and anti-CD25 antibodies in a patient with chronic graft-versus-host disease. Bone Marrow Transplant, 30:327-9.

Tauber J, Sainz de la Maza M, Foster CS. 1991. Systemic chemotherapy for ocular cicatricial pemphigoid. Cornea, 10:185-95.

Thorne JE, Anhalt GJ, Jabs DA. 2004. Mucous membrane pemphigoid and pseudopemphigoid. Ophthalmology, 111:45-52.

Thorne JE, Jabs DA, Qazi FA, et al. 2005. Mycophenolate mofetil therapy for inflammatory eye disease. Ophthalmology, 112:1472-7.

Tseng SC, Di Pascuale MA, Liu DT, et al. 2005. Intraoperative mitomycin $\mathrm{C}$ and amniotic membrane transplantation for fornix reconstruction in severe cicatricial ocular surface diseases. Ophthalmology, 112:896-903.

Tsubota K, Satake Y, Ohyama M, et al. 1996. Surgical reconstruction of the ocular surface in advanced ocular cicatricial pemphigoid and StevensJohnson syndrome. Am J Ophthalmol, 122:38-52.

Tugal-Tutkun I, Akova YA, Foster CS. 1995. Penetrating keratoplasty in cicatrizing conjunctival diseases. Ophthalmology, 102:576-85.

Tyagi S, Bhol K, Natarajan K, et al. 1996. Ocular cicatricial pemphigoid antigen: partial sequence and biochemical characterization. Proc Natl Acad Sci USA, 93:14714-9.

Urcelay ML, McQueen A, Douglas WS. 1997. Cicatricial pemphigoid treated with intravenous immunoglobulin. Br J Dermatol, 137:477-8.

Wertheim MS, Males JJ, Cook SD, et al. 2006. Dapsone induced haemolytic anaemia in patients treated for ocular cicatricial pemphigoid. $\mathrm{Br} J$ Ophthalmol, 90:516.

Whiteside OJ, Martinez Devesa P, Ali I, et al. 2003. Mucous membrane pemphigoid: nasal and laryngeal manifestations. J Laryngol Otol, 117:885-8.

Wieme N, Lambert J, Moerman M, et al. 1999. Epidermolysis bullosa acquisita with combined features of bullous pemphigoid and cicatricial pemphigoid. Dermatology, 198:310-13.

Yesudian PD, Armstrong S, Cawood JI, et al. 2005. Mucous membrane pemphigoid: management of advanced ocular disease with intravenous cyclophosphamide and amniotic membrane transplantation. $\mathrm{Br} J$ Dermatol, 153:692-4.

Zurdel J, Aboalchamat B, Zierhut M, et al. 2001. Early clinical results with mycophenolate mofetil in immunosuppressive therapy of ocular pemphigoid. Klin Monatsbl Augenheilkd, 218:222-8. 